\title{
DESENVOLVIMENTO DE UMA FERRAMENTA PARA EDUCAÇÃO NO TRÂNSITO, BASEADO EM TEORIAS DO DESENVOLVIMENTO COGNITIVO DE PIAGET
}

\author{
Walter Aranda Junior, Francisco Assis da Silva, Ana Paula Domeneghetti Parizoto Fabrin
}

Faculdade de Informática (FIPP)- Universidade do Oeste Paulista (UNOESTE), Presidente PrudenteSP.E-mail: anapaula\}@unoeste.br

\section{RESUMO}

Nos tempos atuais pode-se observar que a relação Homem $x$ Trânsito não está na mais perfeita harmonia, devido ao fato do homem não possuir em sua infância uma base estrutural com suporte às ferramentas computacionais para apoio na área de psicologia, no tocante à educação de crianças para o trânsito. Com esta problemática observa-se que é necessário o desenvolvimento de uma aplicação utilizando recursos tecnológicos para área educacional do trânsito direcionado às crianças. A complexidade da aplicação deve atender aos princípios abordados pela Teoria do Desenvolvimento cognitivo de Piaget, uma vez que trata dos aspectos cognitivos, que auxilia na capacidade de manipular os componentes de um computador.

Palavras-chave: Jogo educacional - Software educacional - Software geografia

\section{DEVELOPMENT OF A TOOL FOR TRAFFIC EDUCATION, BASED ON PIAGET'S THEORIES OF COGNITIVE DEVELOPMENT}

\begin{abstract}
Nowadays can be observed that the relation of Man $x$ Traffic is not in perfect harmony, due to the fact the man does not possess in its childhood a structural support to computational tools to help in a psychology area for to education children to traffic. With this problematic it is necessary to develop an application using technological resources for the educational area of traffic directed to children. The complexity of application must attend the principles addressed by cognitive development theory of Piaget, since it deals with cognitive aspects, helping in ability to manipulate the components of a computer.
\end{abstract}

Keywords: educational game -educational Software -Software for geography 


\section{INTRODUÇÃO}

Nos dias de hoje, observa-se um grande crescimento na taxa de acidentes de trânsito, conforme pesquisa realizada pelo Ministério Federal dos Transportes (2010), sobre a estatística alarmante de acidentes de trânsito nas rodovias Federais entre 1998 a 2002. De acordo com a pesquisa, foi mostrado que há uma grande necessidade de melhorias no comportamento do motorista e do pedestre, que deve ser feito de maneira urgente.

Em pesquisa realizada por Rozestraten (1998), pode-se concluir ainda, que o cargo de Psicólogo do Trânsito é uma área que, até mesmo nos dias de hoje, não está muito bem desenvolvida no Brasil, no que diz respeito às atribuições relacionada aos órgãos do Governo Federal. Também há uma grande necessidade de se melhorar os estudos e as validações de testes de avaliação psicológica nos grupos de motoristas pluri-acidentados e não acidentados [Rozestraten 1998]. De acordo com esse estudo, há uma grande necessidade de pesquisas que priorizem a área da psicologia do trânsito atualmente. Rozestraten (1998) também coloca em destaque que, essa necessidade por estudos está ligada em alguns fatores centrais, tais como: erros dos condutores, dos pedestres e das condições do condutor.

Em relação às condições ruins no trânsito, que faz aumentar o número de mortes e traz grandes prejuízos para a população, pode ser amenizada por meio da educação começando já nos primeiros anos de vida da criança. De acordo com o exposto, pode-se perceber a necessidade de um programa educacional envolvendo crianças que, segundo Piaget (1990), estariam na faixa compreendida no período de desenvolvimento que se intitula de operatório concreto e operatório formal, ou seja, crianças com idade acima de 7 anos.
Segundo Parra (1983), uma criança que se inicia no período operatório concreto já possui a capacidade motora para o uso adequado de um computador, sendo que já possui os movimentos de pinça, ou a coordenação motora fina, que responde a manipulação dos controles do mouse e do teclado. Portanto, é com essa linha de pensamento que este trabalho propõe, em relação às medidas educacionais, a criação e o desenvolvimento de uma ferramenta computacional que dê suporte e atenda a demanda educacional do trânsito para crianças na faixa de idade anteriormente exposta.

As teorias piagetianas contribuiriam na elaboração adequada de um jogo para uma criança de uma determinada faixa etária, respeitando suas estruturas cognitivas já formadas e aptas para o aprendizado, uma vez que essas teorias são consistentes e completas na questão do desenvolvimento cognitivo [Cunha 2008]. Além disso, o fato de se criar tal conceito de jogo, traria também a possibilidade de estabelecer comparações técnicas envolvendo o jogo ideal proposto e os jogos disponíveis na internet, permitindo depois a confirmação de hipótese levantada anteriormente, de que tais jogos não apresentam, até 0 momento, fundamentação teórica relevante de apoio educacional no trânsito.

A utilização de algumas ferramentas computacionais pelas crianças, propicia um aprendizado em curto prazo. Focalizando-se a atenção delas por meio da interação com animações e recursos computacionais disponíveis atualmente como é o caso do Silverlight da Microsoft (utilizado como base para 0 desenvolvimento deste trabalho) é possível a criação de uma ferramenta que faça a interface entre o divertimento e a aprendizagem, gerando informação para permitir aos psicólogos análises das deficiências de aprendizagem das crianças. 


\section{TRABALHOS RELACIONADOS}

Atualmente, toda e qualquer tecnologia que possui potencialidades e características de comunicação e manipulação de informações, parece adequar-se perfeitamente às atividades ligadas à educação, na medida em que $\mathrm{o}$ ato de ensinar/aprender consiste, sobretudo em uma relação de comunicação por excelência [Teixeira e Brandão 2003].

Com a evolução da tecnologia que cresce a cada dia e as crianças cada vez mais cedo aprendendo a usar o computador, acredita-se na facilidade de aplicar jogos para educação dessas crianças com 0 acompanhamento de especialistas. Esses jogos vêm como modo de entretenimento e diversão, porém, seu conteúdo contêm aspectos educacionais que permitem a assimilação de conhecimentos, informações, valores e atitudes para a educação no trânsito [Fabrin 2010].

A aplicação desses softwares de jogos com interação e recepção com os usuários finais (em especial crianças e jovens) vem sendo desenvolvida mundialmente. Esses jogos são chamados de Serious Games (jogos de aprendizagem) [Tavares 2006].

Fabrin (2010) realizou pesquisas sobre ferramentas on-line e gratuitas existentes que auxilia na educação no trânsito, e desta forma foi possível observar que não foi ainda desenvolvida uma ferramenta ideal, que possa englobar todos os quesitos necessários para uma boa educação no trânsito. Esses quesitos compreendem: embasamentos teóricos, adequação para uma faixa etária específica e eficácia do jogo para 0 treinamento no trânsito com adolescentes.

Também foi possível observar ferramentas na Web com visão teórica de educação no trânsito como uma ferramenta ideal capaz de entreter e também de ensinar [Fabrin 2010].
Desta maneira, as ferramentas que foram observadas e que ainda não contém todos os quesitos necessários para uma educação ideal no trânsito como este projeto propõe, são apresentadas na sequência.

A Figura 1 apresenta uma ferramenta desenvolvida pelo Detran para verificar se o usuário tem informações básicas sobre as regras de trânsito, por meio de perguntas e respostas de múltipla escolha. Esta ferramenta pode ser encontrada em: http://www.detran.se.gov.br/jogos_desafio.asp [Fabrin 2010].

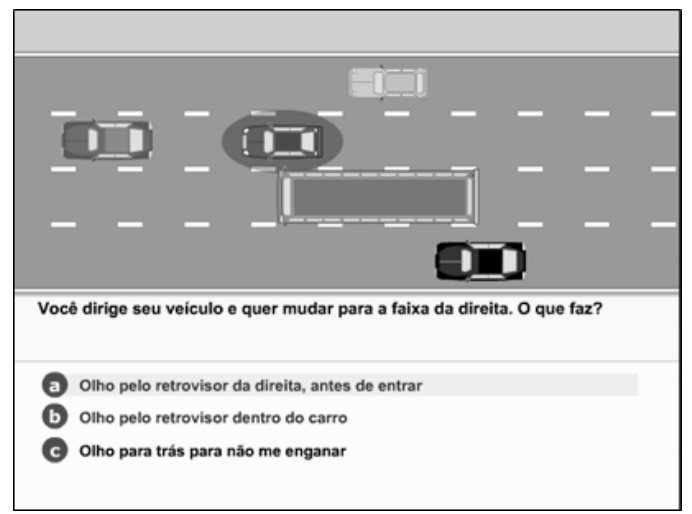

Figura 1. Jogo Desafio do Trânsito

$\mathrm{Na}$ Figura 2 é apresentada outra ferramenta desenvolvida pelo Detran, em que avalia a capacidade do usuário na compreensão sobre sinalização de trânsito, por meio da escolha de letras para formarem palavras e ou frases relacionadas com as sinalizações de trânsito brasileira. Esta ferramenta pode ser encontrada em: http://www.detran.se.gov.br/jogos_forca.asp [Fabrin 2010].

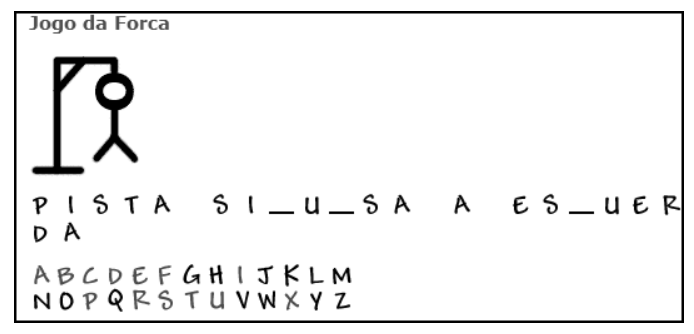

Figura 2. Jogo da Forca 
A Figura 3, apresenta uma terceira ferramenta desenvolvida pelo Detran, em que se verifica a capacidade do usuário em memorizar objetos, sendo que cada "carta" é um objeto relacionado ao trânsito. Esta ferramenta pode ser encontrada em: http://www.detran.se.gov.br/jogos_memoria.asp [Fabrin 2010].

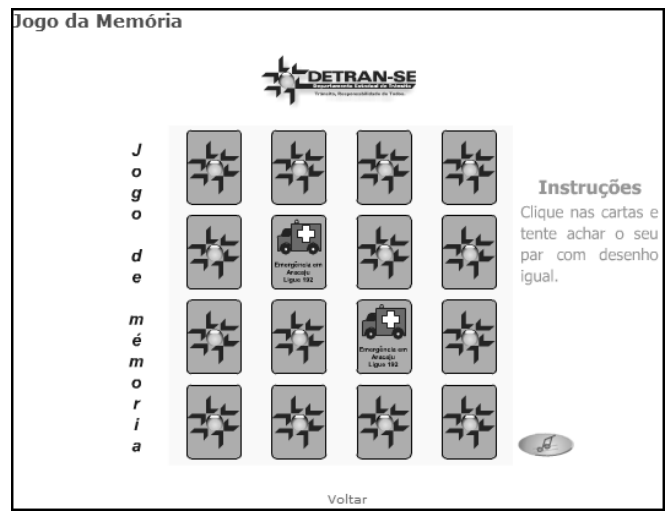

Figura 3. Jogo da Memória

Por sua vez, a Figura 4, apresenta uma ferramenta que tem por finalidade auxiliar na coordenação motora, por meio do controle de um veículo que é controlado pelo o usuário até ser concluída a manobra de estacionar. Esta ferramenta pode ser encontrada em: http://www.freewebarcade.com/game/parkingperfection [Fabrin 2010].

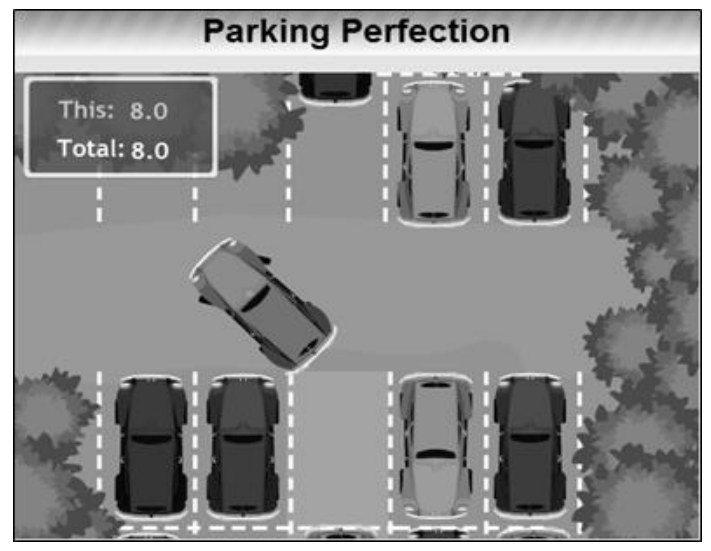

Figura 4. Jogo para coordenação motora de manobras de estacionamento

\section{EDUCAÇÃO NO TRÂNSITO RELACIONADA COM TEORIAS DO DESENVOLVIMENTO COGNITIVO}

A pesquisa realizada a partir das teorias do desenvolvimento cognitivo de Piaget (1982), bem como teorias da aprendizagem de Skinner (2010), proporcionou a elaboração da proposta do modelo da ferramenta para a educação no trânsito deste trabalho. Estas teorias tratam dos aspectos cognitivos da faixa etária que cada criança apresenta para ser capaz de manipular os componentes de um computador e estruturas cognitivas adequadas para que ela possa jogar virtualmente.

De acordo com Piaget (1990), a idade média dos sete anos de idade, que coincide exatamente com 0 começo das atividades escolares que uma criança, começa a ter modificações decisivas no seu desenvolvimento mental ainda de acordo com o autor, pode-se observar as novas formas de organizações das crianças, que as auxilia no que completam as construções esboçadas no decorrer do período precedente, assegurando um equilíbrio estável e que também precede as novas construções [Piaget 1990].

A relação interdependente de uma criança, depois dos seus sete anos, já é capaz de cooperar, porque não confunde o seu ponto de vista com os dos outros, dissociando-os mesmo para coordena-los. As explicações entre as crianças não fica somente entre em ação material, mas também no plano do pensamento. O egocentrismo desaparece quase por totalmente e a espontaneidade já pode ser notada, pela própria estrutura gramatical, a necessidade de conexão entre as idéias e justificação lógica.

O comportamento coletivo de uma criança é a partir dos sete anos, essas mudanças de atitudes sociais podem ser percebidas com o uso de jogos que possuem regras. Com a relação à inteligência, trata-se do início da construção 
lógica, que constitui, precisamente, o sistema de relações que permite a coordenação dos pontos de vista entre si [Piaget 1990].

As primeiras informações sobre os estudos das formações das operações lógicas de uma criança é dividida em duas etapas sucessíveis. A Primeira etapa constitui as operações proposicionais, é a etapa que a criança já começa a fazer proposições lógicas sobre atitudes e é estruturada em conjunto particular de um grupo de quatro informações (identidade, inversão, reciprocidade e correlatividade), só aparece em torno de 11 a 12 anos e só se organiza de forma concisa entre 12 e 15 anos [Piaget 1990].

A outra etapa, que antecede a etapa anterior exposta, vai dos sete a oito anos. Piaget também afirma que desde 7-8 anos se constituem sistemas de operações lógicas que ainda não se referem às proposições como tais, mas, aos próprios objetos, suas classes e suas relações, só se organizando a propósito de manipulações reais ou imaginarias destes objetos [Piaget 1990].

Entre os 11 e 12 anos de idade de uma criança, surge novas operações pela generalização progressiva a partir das procedentes: são as operações da lógica das proposições, que pode a partir dessa etapa, versar sobre enunciados verbais (proposições), sobre objetos. "O raciocínio hipotético-dedutivo torna-se possível, e, com ele, a constituição de uma lógica "formal", quer dizer, aplicável a qualquer conteúdo" [Piaget 1990].

No desenvolvimento da inteligência ainda pode ser notado a continuidade dos processos adquiridos ou mesmo inata, que vem da associação habitual e dos reflexos, sendo que esses processos em que a inteligência se baseia e que ao mesmo tempo em que os utiliza.

O desenvolvimento das estruturas da inteligência pode se dividir em quatro grandes estágios: Inteligência Sensório-Motora;
Inteligência Pré-operatória; Operações Intelectuais Concretas; Operações Intelectuais Formais [Parra 1983].

Todo este trabalho sempre foca as fases que compreendem as crianças acima dos 7 anos porque as operações Intelectuais Concretas (de 7 a 11 anos de idade) traz o mecanismo da reversibilidade lógica e mobilidade ao pensamento da criança. A reversibilidade deste período apresenta-se sob duas formas:

- Negação, ou inversão, que é a anulação de uma operação por sua inversa;

- Reciprocidade: A reciprocidade, expressa na descoberta, pela criança, de operações que compensam a ação original, mas sem anulá-la. Estas formas de reversibilidade são usadas independentemente uma da outra, e elas se reunirão em um sistema unificado apenas no período formal. A conservação da substância, que reflete a presença da reversibilidade, é a primeira da série de conservações do período operatório concreto [Piaget 1967] [Parra 1983].

Uma criança que usa o raciocínio lógico que permanece presa aos objetos e eventos concretos (classificando-os, seriando-os, enumerando-os, entre outros) até os 11 anos de idade, porém o adolescente já possui uma postura um pouco diferente, pode subordinar o real ao possível. "Desta propriedade, Piaget retira todas as demais que caracterizam o pensamento formal" [Parra 1983]. Frente a um problema, o sujeito deste estágio tenta, antes de tudo, imaginar as possíveis relações entre as variáveis e, depois, por meio da experimentação ou, se for o caso, do raciocínio puro, tenta combiná-las segundo um padrão sistemático, para então concluir qual ou quais dessas relações se mantêm como verdadeiras [Parra 1983]. Um 
adolescente que está nesta etapa já tem a capacidade de buscar soluções para problemas.

No nível operatório-concreto, uma criança já consegue conectar em conexões mentais sobre comparações entre comprimento e distância 0 que favorece a aprendizagem para as questões do trânsito e da ferramenta desenvolvida.

Ao nível operatório-concreto (7-11 anos), os sujeitos demonstram uma estratégia cognitiva mais avançada, ordenando os comprimentos, os pesos, a altura, e chegando a julgar as diferenças nas oscilações. Contudo, eles não conseguem dissociar os fatores, fazendo variar, ao mesmo tempo, diversas combinações [Piaget apud Parra 1983].

Ainda sobre as implicações educacionais, já é possui adicionar regras para as crianças seguir a partir dos seus 7 anos de idade.

As regras que governam os agrupamentos das funções cognitivas também dirigem o comportamento afetivo das crianças. Nos jogos coletivos, por exemplo, às crianças de 7-11 anos atuam de maneira mais coordenada e submetem-se ás regras estabelecidas em comum. Podem ser anuladas ou modificadas, segundo a vontade do parceiro. Neste estágio mais que nos anteriores, pode-se notar a presença da cooperação nas relações interindividuais [Piaget apud Parra 1983].

Pode-se notar que a ferramenta computacional desenvolvida é mais adequada acima desta faixa etária, uma vez que a criança já segue as regras postas e já se disponibiliza a jogá-las e respeita os seus limites.

Como foi dito por Parra (1983), na fase de operações formais, o adolescente já pode elaborar a partir de hipóteses.

As operações formais são operações sobre operações. O adolescente organiza os dados da realidade em proposições que podem ser combinadas de várias formas, com a análise combinatória, ele isola cada uma dessas combinações a fim de testá-las. Essas combinações assumem a característica de hipóteses [Piaget apud Parra 1983].

Em relação às características do pensamento formal, descritas em termos verbais, podem ser também descritas em termos das estruturas lógico-matemáticas que Ihes servem como modelos abstratos: "ao nível do pensamento formal (11-15 anos) é onde a presença do paralelismo entre os aspectos social e o lógico se coloca de forma mais destacada" [Piaget apud Parra 1983].

\section{ASPECTO DE IMPLEMENTAÇÃO}

Para a realização deste trabalho foi utilizado o framework Silverlight e a linguagem C\# como tecnologias de desenvolvimento.

Silverlight é um framework desenvolvido pela Microsoft, conhecido anteriormente como WPF/E (Windows Presentation Foundation Everywhere), para construção de RIAs (Rich Internet Applications). RIAs são aplicativos que proporciona uma interface intuitiva e dinâmica, permitindo assim uma maior interatividade com 0 usuário [Arquitetura Silverlight 2010].

Segundo Durães (2010), um grande diferencial no funcionamento da arquitetura RIA do Silverlight é que a interface constituída de um arquivo no formato XAML (eXtensible Application Markup Language) com grande suporte a SEO (Search Engine Optimization) e a codificação é feita no padrão de desenvolvimento de aplicações para o .NET Framework.

A arquitetura do Silverlight está demonstrada na Figura 5. 


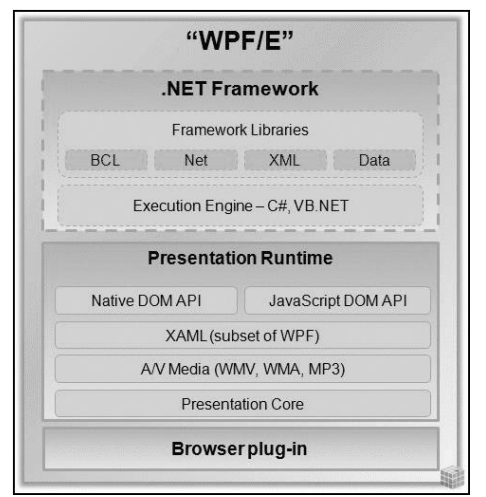

Figura 5. Arquitetura do Silverlight

A Figura 6 demostra a ferramenta desenvolvida com base em fundamentos teóricos da psicologia no trânsito para crianças. Nesta ferramenta há um placar de pontuação que é decrementado de acordo com as violações cometidas nas regras de trânsito, para que o psicólogo que esteja acompanhando uma criança na utilização da ferramenta visualize a quantidade de erros cometidos em uma quantidade de tempo pré-determinado por ele. Também possui um visualizador de violações cometidas de acordo com as regras de trânsito.

A estrutura da tela da ferramenta (cenário) é formada por uma matriz de objetos constituída por 12 colunas e por 8 linhas, como demostrado na Figura 6. Cada posição dessa matriz é um objeto instanciado a partir da classe raiz "scBloco", cada instância de "scBloco" possui um objeto imagem e posições onde se encontra na matriz de objetos. A classe "scBloco" deriva da classe "UserControl" que fornece recursos para manipulação de imagens, criar controles reutilizáveis, ou seja, reutilizar telas ou imagens já implementadas em outras funcionalidades e a possibilidade de criar animações.

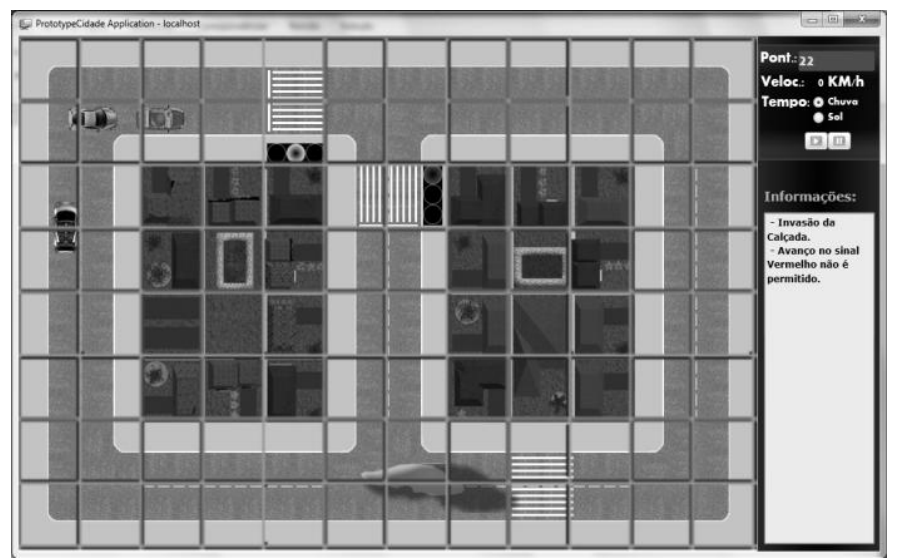

Figura 6. Tela da ferramenta desenvolvida para a educação no trânsito de crianças, formando uma matriz de objetos de $8 \times 12$

A classe "scMat (Figura 7), é responsável por criar a matriz conforme mencionado anteriormente. Também possui a característica de criar um objeto (carrinho) que será controlado pela criança (instanciado a partir da classe "cCarro") e também é responsável pela criação dos objetos interventores do cenário como os carros que percorrem o cenário de forma aleatória.

A classe "scBloco", possui os métodos: Right(), Left(), Up() e Down() responsáveis pela manipulação do objeto (carrinho) que será controlado pela criança no cenário, utilizando as teclas: Direita, Esquerda, Cima e Baixo.

A classe "MainPage" é a classe que será instanciada no momento da execução da ferramenta. Nela é instanciada a classe "GerenciaArvore", essa classe possui a finalidade de gerenciar os objetos interventores do cenário (objetos carrinhos).

$\mathrm{Na}$ classe "GerenciaArvore" possui um loop que percorre uma lista encadeada de objetos 
da classe "Automatico" cujo intuito é gerenciar os objetos (carrinhos) que andam "sozinhos" no cenário. Esse gerenciamento constitui de controlar as rotas que são sorteadas a partir de uma origem até um novo destino ("scBloco"), assim como estabelecer por sorteio uma quantidade de tempo de "repouso" para os objetos (carrinhos) quando estes alcançam seus destinos finais. A movimentação dos objetos (carrinhos) é feita de forma aleatória de acordo com a posição que se encontra no cenário, esta atividade é realizada pelo método "Moviementa()" pertencente à classe "Automatico".
O framework Silverlight possui um recurso que se chama "Storyboard" que é responsável por sincronizar e controlar a execução da ferramenta de forma que todos os objetos instanciados na ferramenta concorrentemente uns com os outros, similar ao controle e "gerenciamento" de "threads". O "Storyboard" foi utilizado na ferramenta com a geração de um loop infinito e a cada loop ele verifica se algum controle de direção (cima, baixo, esquerda, direita) foi acionado e também verifica se houve uma colisão de acordo com as regras de trânsito especificadas.

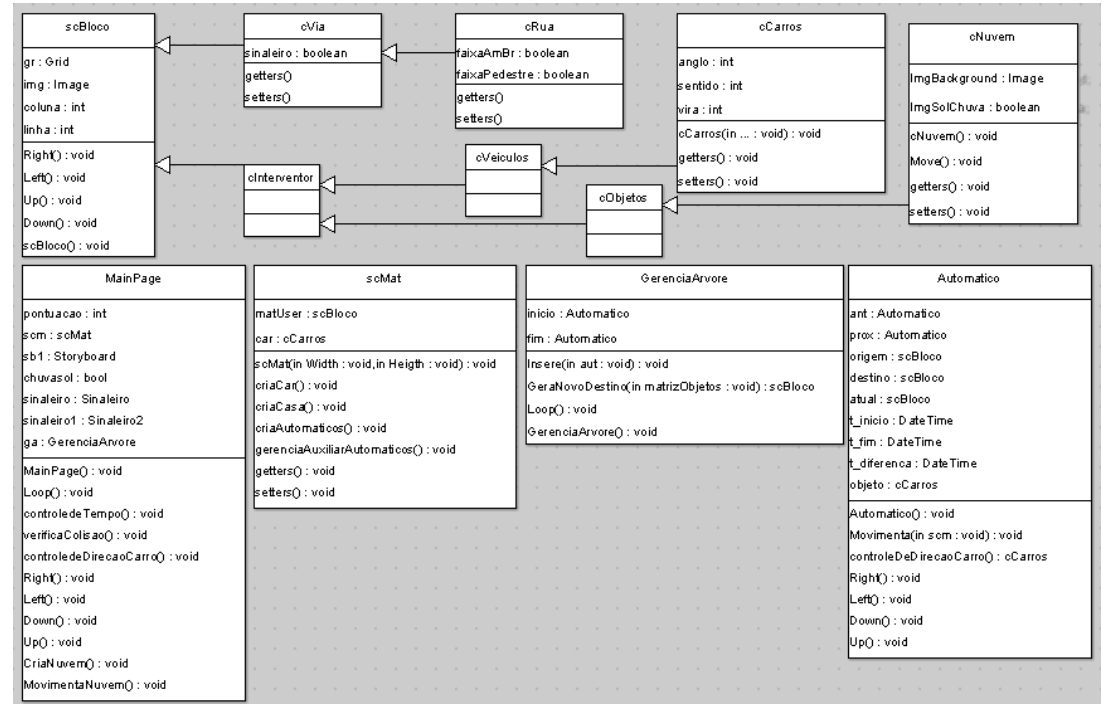

Figura 7. Diagrama de classes da ferramenta desenvolvida

\section{CONCLUSÕES}

O aumento da taxa de acidentes de trânsito trouxe também a preocupação em buscar alternativas que possam fazer diminuir os acidentes de trânsito. Não é preciso muito para entender que uma das razões do crescente aumento de acidentes se deve a necessidade de mudar o comportamento do motorista e do pedestre no trânsito. E a mudança de comportamento deverá vir, certamente, com o desenvolvimento da educação, que pode formar cidadãos mais conscientes e preparados para 0 seu papel, seja do motorista, seja do pedestre, educação que deve vir desde criança. Por esta razão idealizou-se este trabalho que foi desenvolvido com o objetivo de construir uma ferramenta computacional de modo a colaborar e enriquecer a educação no trânsito para as crianças.

A psicologia ampliou estudos que comprovam a capacidade do aprendizado infantil: a linguagem, o pensamento, o raciocínio, as noções de tempo, espaço, movimento e velocidade, memória e inteligência infantil, entre outros. Os estudos do desenvolvimento cognitivo e suas características, explorados por Piaget, trouxe o fundamento teórico para se pensar na criação de uma ferramenta computacional capaz 
de levar a criança uma educação melhor no trânsito.

Com base nos fundamentos teóricos da área da psicologia e estruturados nos estudos da psicologia piagetianas foi possível construir uma ferramenta computacional que se acredita que poderá ser útil na aplicação da educação no trânsito para crianças.

Foi possível, também, demonstrar que por meio de "Jogos" ou ferramentas computacionais que as regras de trânsito podem ser compreendidas no processo educacional, se tiverem por base os fundamentos teóricos da psicologia que muito contribuirão para orientação básica desta mudança de comportamento tanto do motorista, quanto do pedestre, essencial para ajudar a reduzir a taxa tão elevada de acidentes no trânsito.

\section{TRABALHOS FUTUROS}

Algumas melhorias podem ser desenvolvidas para aprimorar a ferramenta para educação no trânsito deste trabalho. Uma delas seria construir um módulo contendo uma interface para criação de cenários e também uma interface de configuração para a seleção de cenários que o usuário poderia utilizar na ferramenta.

Outra melhoria seria a criação de um módulo para poder interligar a ferramenta em rede. Dessa forma, haveria a possibilidade de utilizar a ferramenta em múltiplas localidades e interação de usuários no cenário da ferramenta. Com isso, seria formada uma similaridade ainda maior com o trânsito, pois cada usuário da ferramenta teria que ter o cuidado e respeitar as regras do trânsito além de observar os comportamentos dos outros usuários que estão interligados na rede.

\section{REFERÊNCIAS}

Arquitetura Silverlight. Disponível em: http://www.microsoft.com/silverlight. Aceso em: Março de 2010.
CUNHA, M. V. (2008), Psicologia da Educação, Rio de Janeiro: Lamparina $4^{\text {th }}$ edição.

DURÃES, R. (2010) "Arquitetura Silverlight no .NET", Disponível em: http://imasters.uol.com.br/artigo/6095/aspnet/intro ducao_ao_microsoft_silverlight/. Aceso em abr. de 2010.

FABRIN, A. P. D. P. et al. (2010), Uma análise piagetiana da adequação de jogos sobre trânsito disponibilizados pelos órgãos governamentais. In: ENEPE - XV ENAPI - Encontro Nacional de Pesquisa Institucional - UNOESTE Pres.Prudente. p. 802-802.

Ministério Federal dos Transporte. Disponível em: http://www.transportes.gov.br/Pare/D_Estat.htm. Aceso em abr. de 2010.

PARRA, N. (1983), O adolescente segundo Piaget. São Paulo: Pioneira.

PIAGET, J. (1982), O nascimento da inteligência na criança, Rio de Janeiro: Zahar, $4^{\text {th }}$ edição.

PIAGET, J. (1990), Seis estudos de psicologia, Rio de Janeiro: Forense Universitária $17^{\text {th }}$ edição.

ROZESTRATEN, R. J. A. (1998) "Psicologia do trânsito: conceitos e processos básicos." São Paulo: Ed. Pedagógica e Universitária.

SKINNER, B. F. (2010) "Sobre o Behaviorismo.", São Paulo: Cultrix $12^{\text {th }}$ edição.

TEIXEIRA \& BRANDÃO, A. E. H. G. (2010) "Jogo simbólico: um estudo sobre o brincar da criança em ambientes educacionais." Dissertação de Mestrado em Educação. Disponível em: http://libdigi.unicamp.br/document/?code=vtls0001 34977. Acessado em Março de 2010. 